\title{
Lateral Wall of the Nasopharynx
}

National Cancer Institute

\section{Source}

National Cancer Institute. Lateral Wall of the Nasopharynx. NCI Thesaurus. Code C12244.

The aspect of the nasopharyngeal wall that is located on the side. It contains the pharyngeal opening of the auditory tube. 